\title{
Expression of a recombinant bacterial L-asparaginase in human cells
}

\author{
Raquel Caminha Dantas ${ }^{1}$, Ludmilla Freire Caetano², Ariany Lima Sousa Torres², Matheus Soares Alves', \\ Emanuelly Thays Muniz Figueiredo Silva', Louhanna Pinheiro Rodrigues Teixeira ${ }^{1}$, Daniel Câmara Teixeira' , \\ Renato de Azevedo Moreira', Marcela Helena Gambim Fonseca², Saul Gaudêncio Neto', \\ Leonardo Tondello Martins', Gilvan Pessoa Furtado ${ }^{2}$ and Kaio Cesar Simiano Tavares ${ }^{1 *}$ (1)
}

\begin{abstract}
Objective: L-Asparaginase (ASNase) is an enzyme used in the treatment of acute lymphoblastic leukemia (ALL). As the therapeutic ASNases has bacterial origin, severe side effects are associated with its use, among them hypersensitivity and inactivation of the enzyme. In this context, the objective of this work was to produce a recombinant ASNase of bacterial origin in human cells in order to determine the presence and consequences of potential post-translational modifications on the enzyme.

Results: Recombinant ASNase was expressed in human cells with a molecular weight of $60 \mathrm{kDa}$, larger than in Escherichia coli, which is $35 \mathrm{kDa}$. N-glycosylation analysis demonstrated that the increased molecular weight resulted from the addition of glycans to the protein by mammalian cells. The glycosylated ASNase presented in vitro activity at physiological pH and temperature. Given that glycosylation can act to reduce antigenicity by masking protein epitopes, our data may contribute to the development of an alternative ASNase in the treatment of ALL in patients who demonstrate side effects to currently marketed enzymes.
\end{abstract}

Keywords: L-Asparaginase, Acute lymphoblastic leukemia, Glycosylation, Hypersensitivity

\section{Introduction}

L-Asparaginase is an important biopharmaceutical used in acute lymphoblastic leukemia (ALL) chemotherapy. This disease consists of a heterogeneous group of lymphoid neoplasms that results from monoclonal proliferation and accumulation of immature lymphoblasts in the bone marrow, peripheral blood and other organs [1].

Three formulations of ASNases are currently available on the market. Two are derived from Escherichia coli (native ASNase and pegylated ASNase) and one is derived from the bacterium Erwinia chrysanthemi [2]. Treatment with ASNase may induce undesirable effects in patients, such as blood clotting and gastrointestinal disorders, nerve symptoms, pancreatitis and liver

\footnotetext{
*Correspondence: kaio@unifor.br

${ }^{1}$ Experimental Biology Center (NUBEX), University of Fortaleza (UNIFOR), Fortaleza, Brazil

Full list of author information is available at the end of the article
}

function problems [3]. Anti-ASNase antibody formation may also be related to the development of hypersensitivity or result in silent inactivation of the enzyme and consequent treatment failure [4].

Research and characterization of ASNases in different organisms has been the focus of several studies [5-7]. An as yet little explored possibility is the glycosylation of E. coli ASNase by mammalian cells. Glycosylation may directly act to reduce immunogenicity of proteins [8]. In this work we demonstrate that E. coli ASNase is glycosylated when expressed in mammalian cells, keeping its maximal activity at similar $\mathrm{pH}$ and temperature to those of the non-glycosylated enzyme.

\section{Main text \\ Methods}

Construction of expression vectors

In order to achieve a high expression level of ASNase in HEK-293 cells, the coding sequence of the Escherichia 
coli ansB gene (GenBank Gene ID: 947454), which codes for bacterial L-Asparaginase II, had its codons optimized for expression in mammals through a commercial service (Genscript, Piscataway, USA) and was added from a coding sequence for a signal peptide that directs protein secretion in milk at its N-terminal portion (GenBank Accession Number MN435795). The sequence was then subcloned into the pAdTrack-CMV vector (Addgene \# 16405). The final construct, called pASNase (Fig. 1a), was linearized with the restriction enzyme EcoRI for further transfection into mammalian cells.

For ASNase expression in Escherichia coli, the genomic DNA of Escherichia coli BL21 strain was used as a template to amplify the ansB coding sequence by PCR and ligated into the pET 28a (+) plasmid. E. coli Rosetta DE3 strain, transformed with the pET28a-ansB construct, was used for ASNase expression. The enzyme was purified through a nickel affinity column (Ni-NTA-Promega, Madison, USA).

\section{Production of a mammalian cell line expressing ASNase} HEK-293 cells were electroporated with $5 \mu \mathrm{g}$ of linear pASNase vector in 2 pulses of $1150 \mathrm{~V}$ and $20 \mathrm{mS}$ using the Neon Transfection System (Thermo Fisher Scientific, Waltham, USA). Two days after transfection, cells were collected and redistributed into four 96-well plates at a density of 2 cells/well. Green colonies were split until a pure cell line was obtained. The insertion of the pASNase construct was confirmed by PCR and DNA sequencing.

\section{Expression and detection of recombinant ASNase in mammalian cells}

A HEK-293 cell clone containing ASNase was expanded to ten $100 \mathrm{~mm}$ plates. The medium with ASNase was collected and the recombinant enzyme was concentrated using the Vivaspin 10 MWCO (General Electric Healthcare, Boston, USA) system. Detection of ASNase expression was performed by western blot, using an anti-ASNase polyclonal antibody produced in rabbits (orb344093, Biorbyt, Cambridge, UK) and as the secondary antibody an anti-rabbit-HRP (NA 934, General Electric Healthcare, Boston, USA). The membrane was revealed through chemiluminescence using the Fluorchem FC2 (Protein Simple, San Jose, USA) equipment. As positive control, commercial E. coli ASNase (A3809, Sigma Aldrich) was used.

\section{ASNase Glycosylation Analysis}

The ASNase sequence used for expression in HEK-293 cells was analyzed for potential $\mathrm{N}$-glycosylation sites with

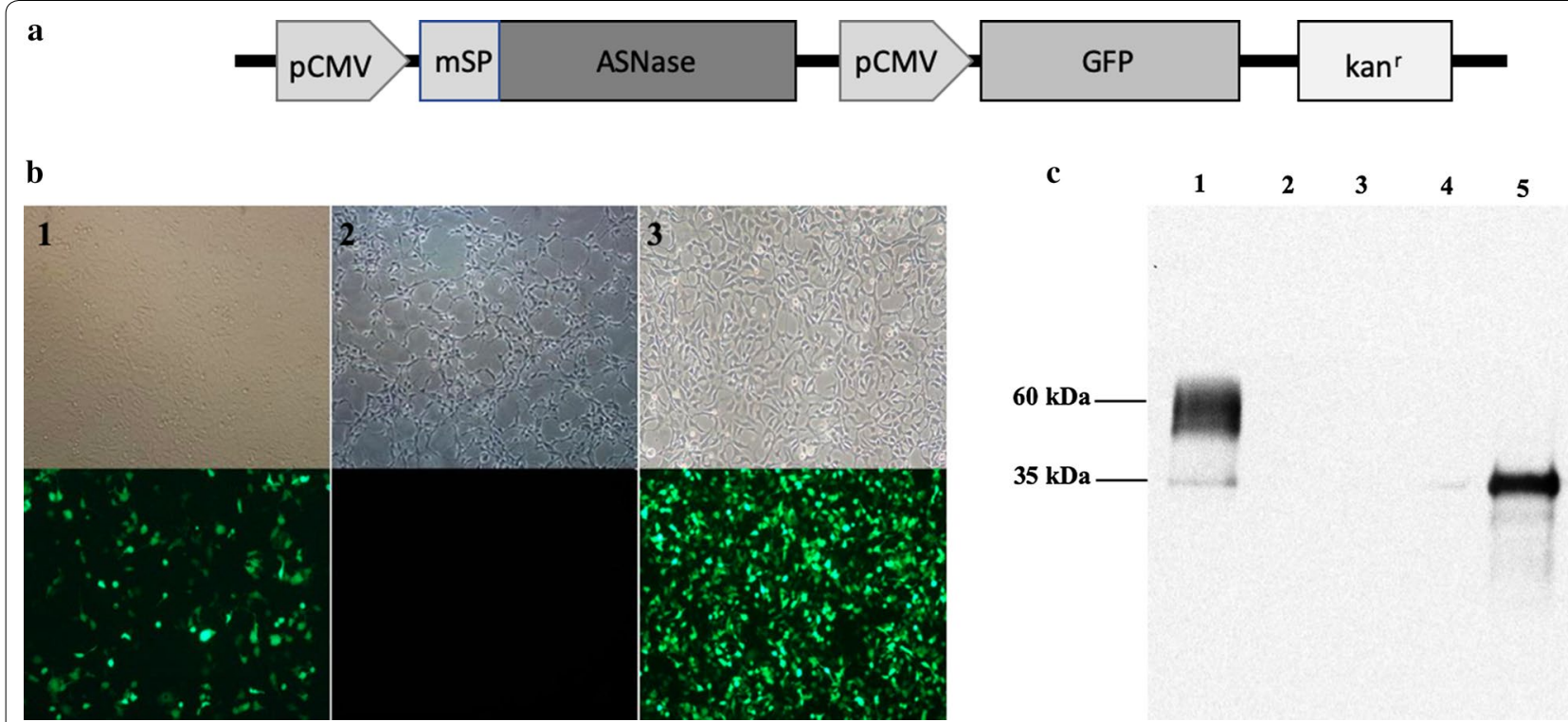

Fig. 1 Bacterial L-asparaginase gene expression in mammalian HEK-293 cells. a pASNase vector, containing two in tandem CMV promoters (pCMV), the coding sequence for the E. coli L-Asparaginase gene (ASNase) with a milk signal peptide sequence (mSP) and a kanamycin resistance gene $\left(\mathrm{kan}^{\mathrm{r}}\right.$ ). b Transfection of HEK-293 cells in white light (top line) and under UV light (bottom line) with the pASNase vector in order to produce clones with the stably integrated transgene. (1) Cells transfected with the linear pASNase plasmid, (2) Cells transfected without DNA (negative control), (3) Cells transfected with a commercial GFP plasmid (positive control). c Immunodetection of recombinant L-Asparaginase secreted in the medium of HEK-293. (1) Cell culture medium from HEK-293 cells transfected with pASNase plasmid, (2) Cell culture medium from HEK-293 cells transfected with no DNA (negative control), (3) Cellular lysate from HEK-293 cells transfected with pASNase plasmid, (4) Cellular lysate from HEK-293 cells transfected with DNA (negative control), (5) Commercial L-Asparaginase from E. coli (positive control) 
NetNGlyc 1.0 software [9]. Samples of ASNase expressed in HEK-293 and E. coli were digested with PNGase-F enzyme (New England Biolabs, Ipswich, USA) according to the manufacturer's instructions. Following digestion, western blot immunodetection of the enzyme was performed as previously described in the section "Expression and detection of recombinant ASNase in mammalian cells", using an anti-ASNase primary polyclonal antibody produced in rabbits (orb344093, Biorbyt, Cambridge, UK) and as the secondary antibody an anti-rabbit-HRP (NA 934, General Electric Healthcare, Boston, USA).

\section{ASNase relative activity}

The ASNase activity was assayed using Nessler's reagent with adaptations for microscale reaction. The assay contained $10 \mu \mathrm{L}$ of dilute enzyme, $10 \mu \mathrm{L}$ of $189 \mathrm{mM}$ L-asparagine solution and $160 \mu \mathrm{L}$ of appropriated buffer. The reaction mixture was incubated at different $\mathrm{pHs}$ and temperatures for $30 \mathrm{~min}$, and then was stopped by adding $10 \mu \mathrm{L}$ of $1.5 \mathrm{M}$ TCA solution. The ammonia released in the supernatant was detected using $10 \mu \mathrm{L}$ of the reaction mixture, $25 \mu \mathrm{L}$ of Nessler's reagent and $215 \mu \mathrm{L}$ of distilled water. The solution was read at $436 \mathrm{~nm}$ using a microplate reader with a 96-well plate. The maximum $\mathrm{pH}$ for the asparaginase activity was determined at $37^{\circ} \mathrm{C}$ in $50 \mathrm{mM}$ of various buffers in $\mathrm{pH}$ ranges of 3-11 (citratephosphate- $\mathrm{pH}$ 3.0-6.0; Tris $\mathrm{pH}$ 7.0-9.0; glycine $\mathrm{pH}$ 10-11). The maximum temperature was determined by incubating the reaction mixture at temperatures ranging from $20{ }^{\circ} \mathrm{C}$ to $90{ }^{\circ} \mathrm{C}$ at $\mathrm{pH} 8.0$, using a thermocycler. All assays were performed in triplicate.

\section{Results}

ASNase expression in mammalian cells

The efficiency of pASNase transfection in HEK-293 cells was estimated in $50 \%$, based on $24 \mathrm{~h}$ GFP expression after electroporation (Fig. 1b). After limiting dilutions of transfected cells, isolation of 11 colonies expressing GFP was possible. Of these, one demonstrated intense and homogeneous GFP expression and was chosen for subsequent experiments.

Expression analysis showed that the ASNase produced by HEK-293 was secreted into the cell culture medium. Two ASNase bands were detected in the cell supernatant, one more intense at $60 \mathrm{kDa}$ and one weaker at $35 \mathrm{kDa}$ (Fig. 1c). Commercial E. coli ASNase showed an intense band at the size of $35 \mathrm{kDa}$.

\section{N-Glycosylation of bacterial ASNase expressed in mammalian cells}

The presence of a larger than expected band size for ASNase expressed in HEK-293 (Fig. 1c) evidenced the possibility of glycosylation in the enzyme. Computational analysis predicted the possibility of 6 potential N-glycosylation sites in the ASNase sequence used (Fig. 2a). To confirm the presence of glycans in the ASNase expressed in mammalian cells, the enzyme was digested with the enzyme PNGase-F, which cleaves N-glycosylations anchored to the protein backbone. The result confirmed the presence of $\mathrm{N}$-glycosylation in the enzyme, which was $35 \mathrm{kDa}$ in size, similar to the $E$. coli ASNase, after treatment with glycosidase (Fig. 2b).

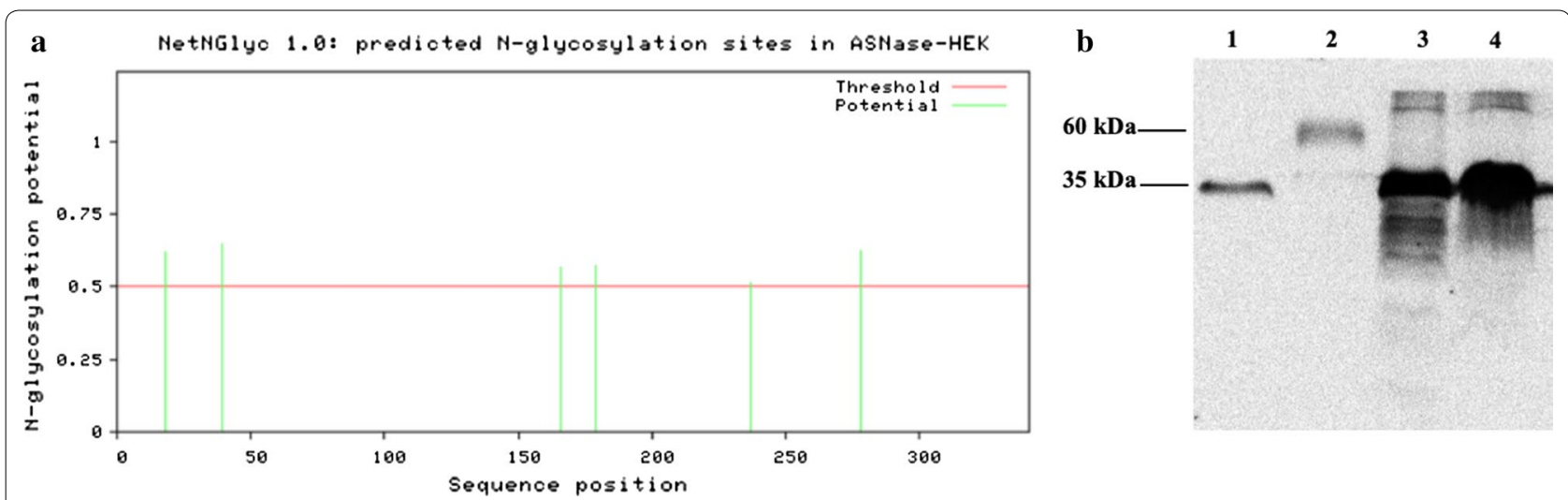

Fig. 2 Glycosylation analysis of the bacterial L-Asparaginase expressed in the mammalian cell line HEK-293. a Predicted N-glycosylation sites in the L-Asparaginase sequence expressed in HEK-293 cells using the NetNGlyc 1.0 software. A position with the potential (vertical lines) crossing the threshold (horizontal line at 0.5) is predicted when glycosylated. b Immunodetection of recombinant L-Asparaginase expressed in HEK-293 cells and E. coli after deglycosylation with PNGase-F. (1) HEK-293 L-Asparaginase treated with PNGase-F, (2) HEK-293 L-Asparaginase untreated with PNGase-F, (3) E. coli L-Asparaginase treated with PNGase-F, (4) E. coli L-Asparaginase untreated with PNGase-F 


\section{Glycosylated ASNase relative activity at different $\mathrm{pHs}$ and temperatures}

L-Asparaginases expressed in E. coli and HEK-293 had very similar relative activity profiles at the different $\mathrm{pH}$ conditions and temperatures tested. Both showed a maximum activity temperature of $60{ }^{\circ} \mathrm{C}$ and a slight variation in the $\mathrm{pH}$ of maximum activity, with 8.0 and 8.5 for the enzymes expressed in HEK-293 and E. coli, respectively (Fig. 3).

\section{Discussion}

The active form of the enzyme encoded by the $a n s B$ gene in $E$. coli is a tetramer, having four identical subunits of $35.6 \mathrm{kDa}$ each [10]. In our results, the ASNase expressed in HEK-293 mammalian cells had two bands, one of $35 \mathrm{kDa}$ and a more intense at $60 \mathrm{kDa}$, present only in mammalian cell culture medium (Fig. 1c). This difference could be associated with glycosylation, since the addition of sugars to the protein chain may alter its electrophoretic migratory pattern [11].

In fact, our results confirmed the presence of $\mathrm{N}$-glycosylation in ASNase expressed in mammalian cells, since after treatment with PGNase-F, the size of the enzyme detected in western blot changed from $60 \mathrm{kDa}$ to $35 \mathrm{kDa}$, the same as the ASNase expressed in E. coli (Fig. 2b) and is as expected for the protein backbone. L-Asparaginases from eukaryotic organisms such as fungi can also be glycosylated [12, 13]. However, it is reported that glycosylation patterns different to those in humans can trigger immune responses in patients [14].

According to our results, glycosylated E. coli L-Asparaginase was active under different $\mathrm{pH}$ and temperature conditions. Both glycosylated and native ASNases showed similar optimal relative activities at a temperature
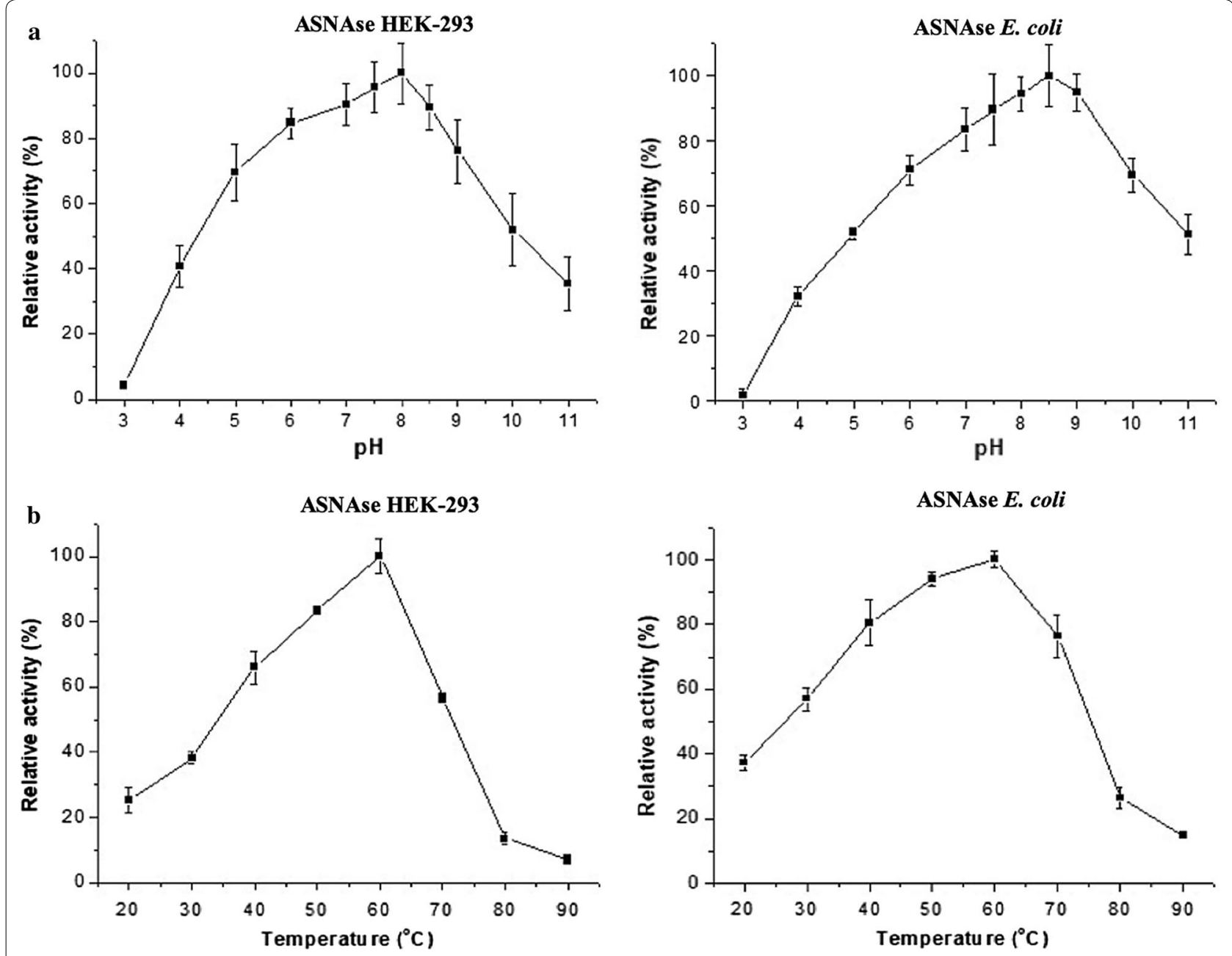

Fig. 3 Bacterial and HEK-293 L-Asparaginase relative activity at different pHs and temperatures. a Effect of the pH on the activity of the glycosylated bacterial L-Asparaginase expressed in the mammalian cell line HEK-293 (left) and in E. coli (right). b Effect of temperature, at pH 8.0, of the glycosylated bacterial L-Asparaginase expressed in the mammalian cell line HEK-293 (left) and in E. coli (right) 
of $60{ }^{\circ} \mathrm{C}$ and a pH range between 8.0 and 8.5 (Fig. 3). Compared with commercially available ASNases, the pegylated enzyme has an optimum temperature of $50{ }^{\circ} \mathrm{C}$ and $\mathrm{pH} 7.0$ [15], while the ASNase produced by E. chrysanthemi shows maximum activity between $30-40{ }^{\circ} \mathrm{C}$ and $\mathrm{pH} 8.5[16,17]$.

Interestingly, reports in the literature show that glycans may mask epitopes present in the protein chain. The human granulocyte colony stimulating factor produced in mammalian cells was not recognized by patient antibodies, while the same biopharmaceutical produced in bacteria and yeast was reactive $[18,19]$. In addition, the incorporation of glycosylation sites in bovine beta-lactoglobulin, considered the main allergen of bovine milk, reduced its immunogenicity in mice, which was attributed to the coverage of protein epitopes by sugars [20]. In this context, our results suggest that the E. coli ASNase glycosylated by mammalian cells, after further studies on its antitumor activity and immunogenicity, may represent a possible alternative for ALL patients refractory to the bacterial enzyme treatment.

\section{Limitations}

The limitations of the study were:

- We did not performed experiments to demonstrate the impact of glycosylation on immunogenicity. Our hypothesis is based only in the cited literature.

- Despite our data suggests that the ASNases from $E$. coli and HEK-293 had similar optimal relative activities at different $\mathrm{pH}$ and temperature, the activity assays performed in this work reports relative activity for each enzyme (from E. coli or HEK-293), making it not possible to directly compare the absolute activity level between them.

\begin{abstract}
Abbreviations
ASNase: L-asparaginase; ALL: acute lymphoblastic leukemia; PCR: polymerase chain reaction; PBS: phosphate buffered saline; GFP: green fluorescent protein;
\end{abstract} LB: Luria-Bertani; mSP: milk signal peptide sequence; TCA: trichloroacetic acid.

\section{Acknowledgements}

Not applicable.

\section{Authors' contributions}

RAM, MHGF, SGN, LTM, GPF and KCST designed the experiments and analyzed the data. RCD, LFC, ALST, MSA, ETMFS, LPR and KCST performed the experiments. DCT, RAM LTM, SGN, MHGF and KCST contributed with reagents/ materials. KCST and GPF wrote the paper. All authors read and approved the final manuscript.

\section{Funding}

This work was supported by Edson Queiroz Foundation (FEQ/UNIFOR) [grant number 06/2016]. The grant agency had no role in study design, data collection and analysis, the decision to publish, or the preparation of this manuscript.

\section{Availability of data and materials}

All data generated or analysed during this study are included in this published article.

Ethics approval and consent to participate

Not applicable.

\section{Consent for publication}

Not applicable.

\section{Competing interests}

The authors declare that they have no competing interests.

\section{Author details}

${ }^{1}$ Experimental Biology Center (NUBEX), University of Fortaleza (UNIFOR), Fortaleza, Brazil. ${ }^{2}$ Oswaldo Cruz Foundation (FIOCRUZ), Fortaleza, Brazil.

Received: 8 November 2019 Accepted: 29 November 2019

Published online: 05 December 2019

\section{References}

1. Bhojwani D, Yang JJ, Pui CH. Biology of childhood acute lymphoblastic leukemia. Pediatr Clin North Am. 2015;62:47-60.

2. Shrivastava A, Khan AA, Khurshid M, Kalam MA, Jain SK, Singhal PK. Recent developments in l-asparaginase discovery and its potential as anticancer agent. Crit Rev Oncol Hematol. 2016;100:1-10.

3. Stams WAG, Den Boer ML, Beverloo HB, Meijerink JPP, Stigter RL, Van Wering $E R$, et al. Sensitivity to $L$-asparaginase is not associated with expression levels of asparagine synthetase in $\mathrm{t}(12 ; 21)+$ pediatric ALL. Blood. 2003:101:2743-7.

4. Rizzari C. Shedding light on the asparaginase galaxy. Blood. 2014;123:1976-8. https://doi.org/10.1182/blood-2014-02-553040.

5. Safary A, Moniri R, Hamzeh-Mivehroud M, Dastmalchi S. Highly efficient novel recombinant L-asparaginase with no glutaminase activity from a new halo-thermotolerant Bacillus strain. Bioimpacts. 2019;9:15-23. https ://doi.org/10.15171/bi.2019.03.

6. Ghasemian A, Al-Marzogi A-H, Al-Abodi HR, Alghanimi YK, Kadhum SA, Shokouhi Mostafavi SK, et al. Bacterial L-asparaginases for cancer therapy: current knowledge and future perspectives. J Cell Physiol. 2019. https:// doi.org/10.1002/jcp.28563.

7. Saeed H, Ali H, Soudan H, Embaby A, El-Sharkawy A, Farag A, et al. Molecular cloning, structural modeling and production of recombinant Aspergillus terreus L. asparaginase in Escherichia coli. Int J Biol Macromol. 2018; 106:1041-51.

8. Van Beers MMC, Bardor M. Minimizing immunogenicity of biopharmaceuticals by controlling critical quality attributes of proteins. Biotechnol $\mathrm{J}$. 2012;7:1473-84.

9. Gupta R, Jung E, Brunak S. Prediction of N-glycosylation sites in human proteins. In: Preparation; 2004.

10. Swain AL, Jaskólski M, Housset D, Rao JK, Wlodawer A. Crystal structure of Escherichia coli L-asparaginase, an enzyme used in cancer therapy. Proc Natl Acad Sci USA. 1993;90:1474-8. https://doi.org/10.1073/ pnas.90.4.1474

11. Selcuk Unal E, Zhao R, Qiu A, Goldman ID. N-linked glycosylation and its impact on the electrophoretic mobility and function of the human proton-coupled folate transporter (HsPCFT). Biochim Biophys Acta Biomembr. 2008;1778:1407-14

12. Eisele N, Linke D, Bitzer K, Naamnieh S, Nimtz M, Berger RG. The first characterized asparaginase from a basidiomycete, Flammulina velutipes. Bioresour Technol. 2011;102:3316-21.

13. De Castro Girão LF, Da Rocha SLG, Sobral RS, Dinis Ano Bom AP, Franco Sampaio AL, Da Silva JG, et al. Saccharomyces cerevisiae asparaginase II, a potential antileukemic drug: purification and characterization of the enzyme expressed in Pichia pastoris. Protein Expr Purif. 2016;120:118-25. 
14. Zhou Q, Qiu H. The mechanistic impact of N-glycosylation on stability, pharmacokinetics, and immunogenicity of therapeutic proteins. J Pharm Sci. 2019;108:1366-77.

15. Wada H, Imamura I, Sako M, Katagiri S, Tarui S, Nishimura H, et al. Antitumor enzyme: polyethylene glycol-modified asparaginase. Ann NY Acad Sci. 1990;613:95-108.

16. Kelo E, Noronkoski T, Stoineva IB, Petkov DD, Mononen I.

$\beta$-Aspartylpeptides as substrates of $\mathrm{L}$-asparaginases from Escherichia coli and Erwinia chrysanthemi. FEBS Lett. 2002:528:130-2.

17. Papageorgiou AC, Posypanova GA, Andersson CS, Sokolov NN, Krasotkina J. Structural and functional insights into Erwinia carotovora L-asparaginase. FEBS J. 2008;275:4306-16.

18. Gribben JG, Devereux S, Thomas NS, Keim M, Jones HM, Goldstone AH, et al. Development of antibodies to unprotected glycosylation sites on recombinant human GM-CSF. Lancet (London, England). 1990;335:434-7. https://doi.org/10.1016/0140-6736(90)90665-r.

19. Hermeling S, Crommelin DJA, Schellekens H, Jiskoot W. Structureimmunogenicity relationships of therapeutic proteins. Pharm Res. 2004;21:897-903.

20. Tatsumi Y, Sasahara Y, Kohyama N, Ayano S, Endo M, Yoshida T, et al. Introducing site-specific glycosylation using protein engineering techniques reduces the immunogenicity of $\beta$-lactoglobulin. Biosci Biotechnol Biochem. 2012;76:478-85. https://doi.org/10.1271/bbb.110753.

\section{Publisher's Note}

Springer Nature remains neutral with regard to jurisdictional claims in published maps and institutional affiliations.
Ready to submit your research? Choose BMC and benefit from:

- fast, convenient online submission

- thorough peer review by experienced researchers in your field

- rapid publication on acceptance

- support for research data, including large and complex data types

- gold Open Access which fosters wider collaboration and increased citations

- maximum visibility for your research: over $100 \mathrm{M}$ website views per year

At BMC, research is always in progress.

Learn more biomedcentral.com/submissions 